Author: POLYAKOV Vladimir Nikolayevich, Doctor of Engineering, Professor, Chief Researcher of the Center for Oil and Gas Technologies and New Materials, Institute for Strategic Studies of the Republic of Bashkortostan; Prospect Oktyabrya, 129/3, Ufa, Republic of Bashkortostan, Russian Federation, 450075, e-mail: intnm@ya.ru;

Author: ZEIGMAN YURIY VENIAMINOVICH, Doctor of Engineering, Professor, Ufa State Petroleum Technological University, Kosmonavtov St., 1, Ufa, Bashkortostan Republic, Russia, 450062, E-mail: jvzeigman@ya.ru;

Author: KOTENEV Yuriy Alekseevich, Doctor of Engineering, Professor, Head of the Chair «Geology and Exploration of Oil and Gas Fields», Ufa State Petroleum Technological University; Kosmonavtov St., 1, Ufa city, Republic of Bashkortostan, Russian Federation, 450062, E-mail: geokot@inbox.ru; Author: MUKHAMETSHIN Vyacheslav Vyacheslavovich, PhD in Engineering Sciences, Associate Professor at the Department of «Oil and Gas\&Oil Field Development and Operation», Ufa State Petroleum Technological University; Kosmonavtov St., 1, Ufa, Republic of Bashkortostan, Russian Federation, 450062, e-mail: vv@of.ugntu.ru;

Author: SULTANOV Shamil Khanifovich, Doctor of Engineering, Professor of the Chair «Geology and Exploration of Oil and Gas Fields»; Ufa State Petroleum Technological University; Mendeleev str., bld.195, office 113, Ufa, Republic of Bashkortostan, Russian Federation, 450080,

e-mail: ssultanov@mail.ru;

Author: CHIZHOV Alexander Petrovich, Candidate of Technical Sciences, Associate Professor, Leading Researcher of the Center for Oil and Gas Technologies and New Materials of the State Autonomous Scientific Institution «Institute for Strategic Studies of the Republic of Bashkortostan»; Prospect Oktyabrya, 129/3, Ufa, Republic of Bashkortostan, Russian Federation, 450075, e-mail:4ap@list.ru

\title{
SYSTEM SOLUTION FOR TECHNOLOGICAL PROBLEMS OF WELL CONSTRUCTION COMPLETION
}

\section{ExTEnded Abstract:}

The paper highlights the factors impeding the technology of well cementing in the well construction process, summarizes the indicators and problems of casing cementing job quality. Based on the analysis of thermodynamic processes running in casing cementing, it is shown that poor quality of well cementing is caused by irreversible processes of destruction of initial properties in cementing slurry-stone that characterize traditional technologies of unsystematic nature.

An alternative to traditional technologies is technology based on system principles, including a complex of multitechnologies applied in wellbore hydromechanical hardening. The complex excludes occurrence of various compli- 
cations (up to $40 \mathrm{~m}^{3} / \mathrm{h}$ absorption, gas oil and water manifestations, fountains, emissions, instability and hydraulic fracturing of rocks) in the construction of oil and gas wells in various geological and technical conditions.

The paper marks the advantages of the multitechnological complex respect to the traditional methods of wells completion.

In the process of well operation, the multitechnological complex prevents occurrence of stuck fluid and cross-flows. Wells introduced from drilling are characterized by higher production rates and lowered, by more than twice, water cut of the extracted produxts, that provides a nonlinear increase of oil recovery factor.

Key words: technological problems, well cementing, quality, cementing, casing columns, multitechnology.

DOI: dx.doi.org/10.15828/2075-8545-2018-10-1-72-87

MACHINE-READABLE INFORMATION ON CC-LICENSES (HTML-CODE) IN METADATA OF THE PAPER

$<$ a rel="license" href="http://creativecommons.org/licenses/by/4.0/" $><$ img alt="Creative Commons License" style="borderwidth:0" src="https://i.creativecommons.org/l/by/4.0/88x31.png" / $></ \mathrm{a}><$ br $/><$ span xmlns:dct="http://purl.org/dc/ terms/" href="http://purl.org/dc/dcmitype/Text" property="dct:title" rel="dct:type" $>$ System solution for technological problems of well construction completion $</$ span $>$ by $<$ a xmlns:cc="http://creativecommons.org/ns\#" href="Nanotehnologii v stroitel'stve $=$ Nanotechnologies in Construction. 2018, Vol. 10, no. 1, pp. 72-87. DOI: dx.doi.org/10.15828/2075-85452018-10-1-72- 87" property="cc:attributionName" rel="cc:attributionURL">Polyakov V.N., Zeigman Yu.V., Kotenev Yu.A., Mukhametshin V.V., Sultanov Sh.Kh., Chizhov A.P. </a $>$ is licensed under a $<$ a rel="license" href="http:// creativecommons.org/licenses/by $/ 4.0 / ">$ Creative Commons Attribution 4.0 International License $</ \mathrm{a}>.<$ br $/>$ Based on a work at <a xmlns:dct="http://purl.org/dc/terms/" href=" http://nanobuild.ru/en_EN/nanobuild-1-2018/" rel="dct:source">

http://nanobuild.ru/en_EN/nanobuild-1-2018/</a $>$. $<$ br $/>$ Permissions beyond the scope of this license may be available at $<$ a xmlns:cc="http://creativecommons.org/ns\#" href="jvzeigman@ya.ru" rel="cc:morePermissions" $>$ jvzeigman@ya.ru $</ a>$.

\section{References:}

1. Polyakov V.N., Ishkaev R.K., Lukmanov R.R. Tekhnologiya zakanchivaniya neftyanykh i gazovykh skvazhin [Oil and gas wells completion technique]. Ufa: TAU, 1999. 408 p. (In Russian).

2. Mirzadzhanzade A.Kh., Karaev A.K., Shirinzade S.A. Gidravlika v burenii i tsementirovanii skvazhin [Hydraulics in oil well drilling and cementing]. Moscow, Nedra, 1977. 230 p. (In Russian).

3. Mukhametshin V.V., Kadyrov R.R. Vliyanie nanodobavok na mekhanicheskie i vodoizoliruyushchie svoystva sostavov na osnove tsementa [Influence of nanoadditives on mechanical and isolating properties of cement-based compositions]. Nanotehnolo- 
gii v stroitel'stve $=$ Nanotechnologies in Construction, 2017. Vol. 9, № 6. P. 18-36. DOI: dx.doi.org/10.15828/2075-8545-2017-9-6-18-36. (In Russian).

4. Andreev A.V., Mukhametshin V.Sh., Kotenev Yu.A. Deposit Productivity Forecast in Carbonate Reservoirs with Hard to Recover Reserves. SOCAR Proceedings, 2016. № 3. P. 40-45. DOI: dx.doi.org/10.5510/OGP20160300287. (In Russian).

5. Zeigman Yu.V., Mukhametshin V.Sh., Khafizov A.R., Kharina S.B. Prospects of Application of Multi-Functional Well Killing Fluids in Carbonate Reservoirs. SOCAR Proceedings, 2016. № 3. P. 33-39. DOI: dx.doi.org/10.5510/OGP20160300286. (In Russian).

6. Mukhametshin V.V., Andreev V.E., Dubinsky G.S., Sultanov Sh.Kh.,Akhmetov R.T. The Usage of Principles of System Geological-Technological Forecasting in the Justification of the Recovery Methods. SOCAR Proceedings, 2016. № 3. P. 46-51. DOI: dx.doi. org/10.5510/OGP20160300288. (In Russian).

7. Akhmetov R.T.,Andreev A.V., Mukhametshin V.V. Metodika prognoza ostatochnoj neftenasyshchennosti i koefficienta vytesneniya po dannym geofizicheskih issledovanij dlya ocenki effektivnosti primeneniya nanotekhnologij [Residual oil saturation and the displacement factor prediction methodology based on geophysical studies data to evaluate efficiency of nanotechnologies application]. Nanotehnologii v stroitel'stve = Nanotechnologies in Construction, 2017. Vol. 9, № 5. P. 116-133. DOI: dx.doi. org/10.15828/2075-8545-2017-9-5-116-133. (In Russian).

8. Zeigman Yu.V., Mukhametshin V.Sh., Sergeev V.V., Kinzyabaev F.S. Eksperimental'noe issledovanie vyazkostnyh svojstv emul'sionnyh sistem s soderzhaniem nanochastic $\mathrm{SiO} 2$ [Experimental study of viscosity properties of emulsion system with $\mathrm{SiO}_{2}$ nanoparticles]. Nanotehnologii v stroitel'stve $=$ Nanotehnologies in Construction, 2017. Vol. 9, № 2. P. 16-38. - DOI: dx.doi.org/10.15828/2075-8545-2017-9-2-16-38. (In Russian).

9. Mukhametshin V.Sh., Zeigman Yu.V., Andreev A.V. Ekspress-ocenka potenciala dobyvnyh vozmozhnostej zalezhej dlya opredeleniya effektivnosti primeneniya nanotekhnologij i neobhodimosti stimulirovaniya vvoda ih v razrabotku [Rapid assessment of deposit production capacity for determination of nanotechnologies application efficiency and necessity to stimulate their development]. Nanotehnologii v stroitel'stve $=$ Nanotechnologies in Construction, 2017. Vol. 9. № 3. P. 20-34. DOI: dx.doi.org/10.15828/2075-8545-2017-9-3-20-34. (In Russian).

10. Mukhametshin V.V. Ustranenie neopredelennostey pri reshenii zadach vozdeystviya na prizaboynuyu zonu skvazhin [Eliminating uncertainties in solving bottom hole zone stimulation tasks]. Bulletin of the Tomsk Polytechnic University. Geo Assets Engineering, 2017. Vol. 328, № 7. P. 40-50. (In Russian).

11. Khayredinov N.Sh., Popov A.M., Mukhametshin V.Sh. Povyshenie effektivnosti zavodneniya nizkoproduktivnyh zalezhej nefti v karbonatnyh kollektorah [Increasing the flooding efficiency of poor-producing oil deposits in carbonate collectors]. Neftyanoe khozyaystvo = Oil industry, 1992. № 9. P. 18-20. (In Russian).

12. Mukhametshin V.Sh. Zavisimost' nefteizvlecheniya ot plotnosti setki skvazhin pri razrabotke nizkoproduktivnyh karbonatnyh zalezhej [Dependence of crude-oil recov- 
ery on the well spacing density during development of low-producing carbonate deposits]. Neftyanoe khozyaystvo = Oil industry, 1989. № 12. P. 26-29. (In Russian).

13. Mukhametshin V., Andreev V. Search and Argumentation of Decisions Aimed at Increasing the Efficiency of Bottom-Hole Zone Stimulation in Oil Accumulations with Challenged Reserves. SPE Russian Petroleum Technology Conference. Moscow, Russia, 2017. P. 1-23. DOI: dx.doi.org/10.2118/187785-MS.

14. Polyakov V.N. Trebovaniya, predyavlyaemye k germetichnosti i prochnosti stvola pri zakanchivanii skvazhin mestorozhdeniy Bashkirii [Requirements for wellbore integrity and strength in well completion process in Bashkortostan oil fields]. Neftyanoe khozyaystvo $=$ Oil industry, 1983. № 5. P. 27-28. (In Russian).

15. Polyakov V.N., Lukmanov R.R., Sharipov A.U. et al. Povyshenie effektivnosti razobshcheniya i izolyatsii produktivnykh plastov pri ikh razburivanii [Productive layers segregation and isolation efficiency increasing in their drilling process]. II Drilling: scientific-technical abstract journal. Moscow, VNIIOENG, 1979. № 9. P. 8-12. (In Russian).

16. Polyakov V.N. O vliyanii protsessov destruktsii i degradatsii na tekhnologiyu bureniya i zakanchivaniya skvazhin [On the destruction and degradation processes impact of on the wells drilling and completion technology]. II open scientific-practical conference "Actual problems of oil and gas wells on land and the continental shelf of the Russian Federation construction and repair»: collection of reports. LLC «NPO Bentotechnologies», 2013. P. 113-118. (In Russian).

17. Ashrafyan M.O. Tekhnologiya razobshcheniya plastov v oslozhnennykh usloviyakh [Technology of layers segregation in complicated conditions]. Moscow, Nedra, 1989. 228 p. (In Russian).

18. Polyakov V.N., Kuznetsov Yu.S., Sagidullin I.A., Shulgina N.Yu., Dubrovsky V.S., Khusainov V.M., Khaminov N.I., Akhmetzyanov R.G., Vildanov A.A., Starov O.E. Reshenie problem zakanchivaniya i ekspluatatsii skvazhin v anomal'nykh termodinamicheskikh usloviyakh [The solving of problems of tailing-in and wells operation in abnormal thermodynamic conditions]. Neftyanoe khozyaystvo = Oil industry, 2005 . № 5. P. 104-110. (In Russian).

\section{DeAR COLleagues!}

THE REFERENCE TO THIS PAPER HAS THE FOLLOWING CITATION FORMAT:

PolyakovV.N.,Zeigman Yu.V., Kotenev Yu.A., MukhametshinV.V., Sultanov Sh.Kh., Chizhov A.P. System solution for technological problems of well construction completion. Nanotehnologii v stroitel'stve = Nanotechnologies in Construction. 2018, Vol. 10, no. 1, pp. 72-87. DOI: dx.doi.org/10.15828/2075-8545-2018-10-1-7287. (In Russian). 
Автор: ПОЛЯКОВ Владимир Николаевич, д-р техн. наук, проф., гл. научный сотрудник Центра нефтегазовых технологий и новых материалов Государственного автономного научного учреждения «Институт стратегических исследований Республики Башкортостан»; пр. Октября, 129/3, г. Уфа, Республика Башкортостан, Россия, 450075, e-mail: intnm@ya.ru;

Автор: ЗЕЙГМАН Юрий Вениаминович, проф., д.т.н., зав. каф. разработки и эксплуатации нефтегазовых месторождений, Федеральное государственное бюджетное образовательное учреждение высшего образования «Уфимский государственный нефтяной технический университет»; ул. Космонавтов, 1, г. Уфа, Республика Башкортостан, Россия, 450062, e-mail: jvzeigman@ya.ru;

Автор: КОТЕНЁВ Юрий Алексеевич, д-р техн. наук, проф., зав. каф. геологии и разведки нефтяных и газовых месторождений, Федеральное государственное бюджетное образовательное учреждение высшего образования «Уфимский государственный нефтяной технический университет»; ул. Космонавтов, 1, г. Уфа, Республика Башкортостан, Россия, 450062, e-mail: geokot@inbox.ru;

Автор: МУХАМЕТШИН Вячеслав Вячеславович, канд. техн. наук, доц. каф. «Разработка и эксплуатация нефтяных и газонефтяных месторождений», Федеральное государственное бюджетное образовательное учреждение высшего образования «Уфимский государственный нефтяной технический университет»; ул. Космонавтов, 1, г. Уфа, Республика Башкортостан, Россия, 450062, e-mail:vv@of.ugntu.ru;

Автор: СУЛТАНОВ Шамиль Ханифович, д-р техн. наук, проф. каф. геологии и разведки нефтяных и газовых месторождений, Федеральное государственное бюджетное образовательное учреждение высшего образования «Уфимский государственный нефтяной технический университет»; ул. Менделеева, 195, каб. 113, г.Уфа, Республика Башкортостан, Россия, 450080, e-mail: ssultanov@mail.ru;

Автор: ЧИжов Александр Петрович, канд. техн. наук, доц., ведущий научный сотрудник Центра нефтегазовых технологий и новых материалов Государственного автономного научного учреждения «Институт стратегических исследований Республики Башкортостан»; пр. Октября, 129/3, г. Уфа, Республика Башкортостан, Россия, 450075, e-mail: 4ap@list.ru

\section{СИСТЕМНОЕ РЕШЕНИЕ ТЕХНОЛОГИЧЕСКИХ ПРОБЛЕМ ЗАКАНЧИВАНИЯ СТРОИТЕЛЬСТВА СКВАЖИН}

АННОТАЦИЯ К СТАТЬЕ (АВТОРСКОЕ РЕЗЮMЕ, РЕФЕРАТ):

В работе освещены факторы, нарушающие технологию крепления при строительстве скважин, обобщены показатели и проблемы качества цементирования обсадных колонн. На основе рассмотрения термодинамических процессов цементирования обсадных колонн показано, что проблемы низкого ка- 
чества крепления связаны с необратимыми процессами деструкции исходных свойств тампонажного раствора-камня, характерными для традиционных технологий бессистемного характера.

Альтернативой традиционным технологиям предлагается технология, основанная на системных принципах, включающая комплекс мультитехнологий гидромеханического упрочнения ствола скважин. Комплекс исключает возникновение различных осложнений (поглощения интенсивностью до $40 \mathrm{~m}^{3}$ /ч, газонефтеводопроявления, фонтаны, выбросы, неустойчивость и гидроразрыв горных пород) при строительстве нефтяных и газовых скважин в различных по сложности геолого-технических условиях.

В статье отмечены преимущества комплекса мультитехнологий перед традиционными методами заканчивания скважин.

В процессе эксплуатации скважин комплекс мультитехнологий предупреждает появление заколонных флюидопроявлений и межпластовых перетоков. Скважины, вводимые из бурения, характеризуются более высокими дебитами и пониженной более, чем в два раза, обводненностью добываемой продукции, что обеспечивает нелинейное повышение коэффициента извлечения нефти.

Ключевые слова: технологические проблемы, крепление, качество, цементирование, обсадные колонны, мультитехнология.

DOI: dx.doi.org/10.15828/2075-8545-2018-10-1-72-87

МАШИНОЧИТАЕМАЯ ИНФОРМАЦИЯ о СС-ЛИЦЕНЗИИ В МЕТАДАННЫХ СТАТЬИ (НTML-КОД):

$<$ a rel="license" href="http://creativecommons.org/licenses/by/4.0/"><img alt="Лицензия Creative Commons" style="borderwidth:0" src="https://i.creativecommons.org/l/by/4.0/88x31.png" / $></ \mathrm{a}><$ br $/>$ Произведение «<span xmlns:dct="http:// purl.org/dc/terms/" href="http://purl.org/dc/dcmitype/Text" property="dct:title" rel="dct:type">Системное решение технологических проблем заканчивания строительства скважин $</$ span $>$ » созданное автором по имени $<\mathrm{a}$ xmlns:cc="http:// creativecommons.org/ns\#" href="Нанотехнологии в строительстве. - 2018. - Том 10, № 1. - C. 72-87. - DOI: dx.doi. org/10.15828/2075-8545-2018-10-1-72-87" property="cc:attributionName" rel="cc:attributionURL"> Поляков В.Н., Зейгман Ю.В., Котенёв Ю.А., Мухаметшин В.В., Султанов Ш.Х., Чижов А.П. </a>, публикуется на условиях <a rel="license" href="http://creativecommons.org/licenses/by/4.0/"> лицензии Creative Commons С указанием авторства 4.0 Всемирная $</ \mathrm{a}>$. $<$ br $/>$ Основано на произведении с $<$ a xmlns:dct="http://purl.org/dc/terms/" href="http://nanobuild.ru/ru_RU/ nanobuild-1-2018/" rel="dct:source">http://nanobuild.ru/ru_RU/nanobuild-1-2018/</a>.<br />Разрешения, выходящие за рамки данной лицензии, могут быть доступны на странице <a xmlns:cc="http://creativecommons.org/ns\#" href="jvzeigman@ ya.ru" rel="cc:morePermissions" >jvzeigman@ya.ru</a $>$. 


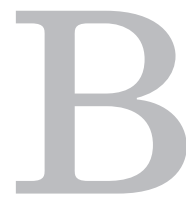

настоящее время отмечается устойчивая тенденция увеличения сложности геолого-технических условий строительства и эксплуатации нефтяных и газовых скважин. Усложняющиеся условия природного и техногенного характера негативно отражаются на показателях качества и эффективности крепления скважин [1-3]. Такая ситуация сложилась из-за двух основных обстоятельств.

Первое обстоятельство связано с закономерным снижением эффективности применения традиционных технологий строительства скважин в непрерывно изменяющихся и аномальных природно-технических условиях с нестационарным термодинамическим характером. Технологии, базирующиеся на принципах поддержания гидравлического равновесия в системе «скважина-массив горных пород», направлены на предупреждение выбросов, газонефтеводопроявлений и стабилизацию условий технологических процессов. Бессистемные подходы и решения в условиях нестационарности гидравлического поведения скважины по характеру, близкому к хаотичному для процессов физико-химического и гидромеханического взаимодействия пластовых флюидов, технологических жидкостей и массива горных пород, приводят к нарушению технического состояния ствола.

Второе - до настоящего времени отсутствуют эффективные методы управления и контроля технологическими процессами строительства и эксплуатации скважин. Отсутствие методов регулирования механизмов гидромеханического воздействия относится и к прискважинным, удаленным зонам проницаемых газонефтеводонасыщенных пластов, поглощающим и неустойчивым интервалам вскрытых горных пород.

Негативными последствиями отмеченных обстоятельств становятся закономерные снижения ключевых показателей строительства и эксплуатации скважин: нарушение герметичности крепи, ухудшение фильтрационных характеристик продуктивных пластов, объединение флюидонасыщенных пластов продуктивной толщи в единый фильтр, заколонные флюидопроявления, обводнение добываемой продукции, 
грифоны и т.д. В конечном счете, все это приводит к снижению интегрального показателя эффективности разработки нефтяных залежей коэффициента извлечения нефти (КИН) - и росту обводненности добываемой продукции [4-13].

Как показывает многолетний опыт, применение традиционных и вновь разрабатываемых технологий не приводит к эффективному решению большинства технологических проблем. Это стало причиной длительного застоя в этой области. Тем не менее, среди большинства специалистов бытует устойчивое мнение, что существующие технологические проблемы в бурении (поглощения, газонефтеводопроявления, неустойчивость горных пород, ухудшение природных коллекторских свойств продуктивных пластов, нарушение герметичности заколонного пространства, крепи и т. д.) могут успешно решаться изменением реологических свойств и параметров технологических жидкостей (буровых, тампонажных и специальных растворов регулированием режимов их циркуляции в скважине, давлений и т.д.).

Однако результаты промысловых исследований и опыт показывают, что подобное мнение не имеет достаточных научных обоснований, не подтверждается практикой и является весьма и весьма спорным по многим обстоятельствам [1].

Аналитическая оценка современного уровня качества и эффективности крепления скважин на разрабатываемых месторождениях страны показывает, что традиционно применяемые технологии цементирования обсадных колонн не обеспечивают технически необходимой долговременной герметичности крепи $[14,17]$. Основные виды брака связаны с разобщением массива горных пород при цементировании заколонного пространства скважин. Это недохождение цементного раствора на расчетную высоту (25-40\% ), неоднородная плотность цементного растворакамня за обсадной колонной (85-95\%), разрыв сплошности цементного кольца (12-20\%), прорыв пластовых флюидов к фильтру при освоении скважин и заколонные перетоки (8-21\% ) (обобщенные интегральные показатели). Из перечисленных видов брака только при наличии неоднородной плотности цементного камня в заколонном пространстве скважин практически исключается возможность крепи (табл. 1). И это является одной из ключевых проблем строительства и эксплуатации скважин.

Основными факторами нарушения исходных свойств тампонажных растворов-камня являются: геолого-физические и гидравлические 
Таблица 1

\section{Результаты оценки качества цементирования эксплуатационных} колонн на месторождениях Западной Сибири (данные СГДТ)

\begin{tabular}{|c|c|c|c|c|c|c|}
\hline \multirow{2}{*}{$\begin{array}{c}\text { Стратиграфиче- } \\
\text { ские свиты }\end{array}$} & \multirow{2}{*}{$\begin{array}{c}\text { Характерные } \\
\text { интервалы } \\
\text { подъема } \\
\text { цемента, м }\end{array}$} & \multicolumn{2}{|c|}{$\begin{array}{c}\text { Показатели плотности } \\
\text { цементного раствора, г } / \text { см }^{3}\end{array}$} & \multicolumn{2}{|c|}{ 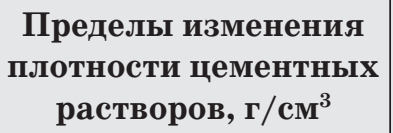 } & \multirow{2}{*}{$\begin{array}{c}\text { Толщина } \\
\text { интерва- } \\
\text { ла, м }\end{array}$} \\
\hline & & исходные & $\begin{array}{c}\text { средние по } \\
\text { СГДТ }\end{array}$ & от & до & \\
\hline $\begin{array}{l}\text { Люлинворская, } \\
\text { талицкая, } \\
\text { ганькинская, } \\
\text { березовская, } \\
\text { кузнецовская, } \\
\text { покурская, } \\
\text { алымская }\end{array}$ & $\begin{array}{c}793-1104 \\
495-529 \\
797-809 \\
1104-1769\end{array}$ & $\begin{array}{l}1,50 \\
1,50 \\
1,50 \\
1,80\end{array}$ & $\begin{array}{l}1,35 \\
1,26 \\
1,28 \\
1,70\end{array}$ & $\begin{array}{l}1,21 \\
1,21 \\
1,28 \\
1,44\end{array}$ & $\begin{array}{c}1,52 \\
1,30 \\
- \\
1,80\end{array}$ & $\begin{array}{c}711 \\
34 \\
12665\end{array}$ \\
\hline $\begin{array}{l}\text { Ганькинская, } \\
\text { березовская, } \\
\text { кузнецовская, } \\
\text { покурская, } \\
\text { алымская, } \\
\text { вартовская }\end{array}$ & $\begin{array}{l}741-2010 \\
899-903 \\
911-914 \\
914-928\end{array}$ & $\begin{array}{l}1,80 \\
1,80 \\
1,80 \\
1,80\end{array}$ & $\begin{array}{l}1,75 \\
1,27 \\
1,36 \\
1,48\end{array}$ & $\begin{array}{l}1,27 \\
1,27 \\
1,36 \\
1,48\end{array}$ & $\begin{array}{l}1,99 \\
- \\
- \\
-\end{array}$ & $\begin{array}{c}1269 \\
4 \\
3 \\
4\end{array}$ \\
\hline $\begin{array}{l}\text { Чеганская, } \\
\text { люлинворская, } \\
\text { талицкая, } \\
\text { ганькинская, } \\
\text { березовская, } \\
\text { кузнецовская, } \\
\text { покурская, } \\
\text { алымская, } \\
\text { вартовская }\end{array}$ & $\begin{array}{c}403-1828 \\
637-663 \\
663-705 \\
783-814 \\
1828-2527\end{array}$ & $\begin{array}{l}1,50 \\
1,50 \\
1,50 \\
1,50 \\
1,80\end{array}$ & $\begin{array}{l}1,38 \\
1,17 \\
1,24 \\
1,30 \\
1,75\end{array}$ & $\begin{array}{l}1,17 \\
1,17 \\
1,25 \\
1,30 \\
1,48\end{array}$ & $\begin{array}{c}1,38 \\
- \\
1,29 \\
- \\
1,99\end{array}$ & $\begin{array}{l}1425 \\
26 \\
42 \\
31 \\
699\end{array}$ \\
\hline
\end{tabular}

условия цементирования обсадных колонн, природные тампонажнотехнические свойства портландцементов, процессы нестационарного термодинамического и физико-химического взаимодействия тампонажных растворов и приствольной зоны горных пород (проницаемых и неустойчивых). Совместное и одновременное воздействие этих факторов приводит к нарушению технологии крепления скважин и снижению показателей технического состояния крепи [16]. Обзор опубликованных в этой области работ показывает, что стабилизация (сохранение) исходных свойств тампонажного раствора и формирование однородного по плотности тампонажного камня в заколонном пространстве в ин- 
тервале цементирования является одной из главных и до настоящего времени не решенных технологических проблем.

Широко применяемые на практике современные технологии физико-химического регулирования свойств тампонажного раствора и камня, а также технические средства разобщения заколонного пространства отличаются низкой эффективностью. Сложившееся положение связано с тем, что в большинстве разработок не учитывается превалирующее влияние на стабильность исходных свойств цементных растворов самой причины - гидравлической связи их с комплексом проницаемых горных пород как при движении в кольцевом пространстве, так и в период ожидания затвердевания цемента (ОЗЦ) [16].

В условиях нестационарного гидродинамического взаимодействия цементного раствора с комплексом флюидонасыщенных пластов и виброволнового (турбулентного) движения его в кольцевом пространстве при цементировании обсадных колонн интенсифицируются процессы, изменяющие исходное водоцементное отношение (В/Ц) тампонажных растворов. Причем ни в динамической стадии процесса цементирования, ни в период ОЗЦ эти изменения В/Ц не контролируются, но однозначно устанавливаются после формирования цементного камня в заколонном пространстве по его плотности с помощью прибора СГДТ (селективный гамма-дефектомер-толщиномер).

На примере цементограммы (см. рис.) и расчетов рассмотрим гидравлические особенности цементирования обсадной колонны и характерные режимы турбулентного течения тампонажных растворов (гельцементного и портландцементного) в кольцевом пространстве скважины.

Анализ зафиксированных на цементограмме изменений параметров процесса цементирования эксплуатационной колонны в реальном времени позволяет установить ряд особенностей гидравлических и температурных условий производства цементировочных работ. Главной из таких особенностей является разрыв сплошности потока цементного раствора и турбулентный (виброволновой) режим движения его в обсадных трубах и заколонном пространстве скважины. Связано это с проявлением гравитационных сил при движении жидкостей различной плотности в вертикальном или наклонном канале (ствол скважины). Гравитационный режим движения бурового и тампонажного растворов в скважине с разрывом сплошности потока возникает при достижении 


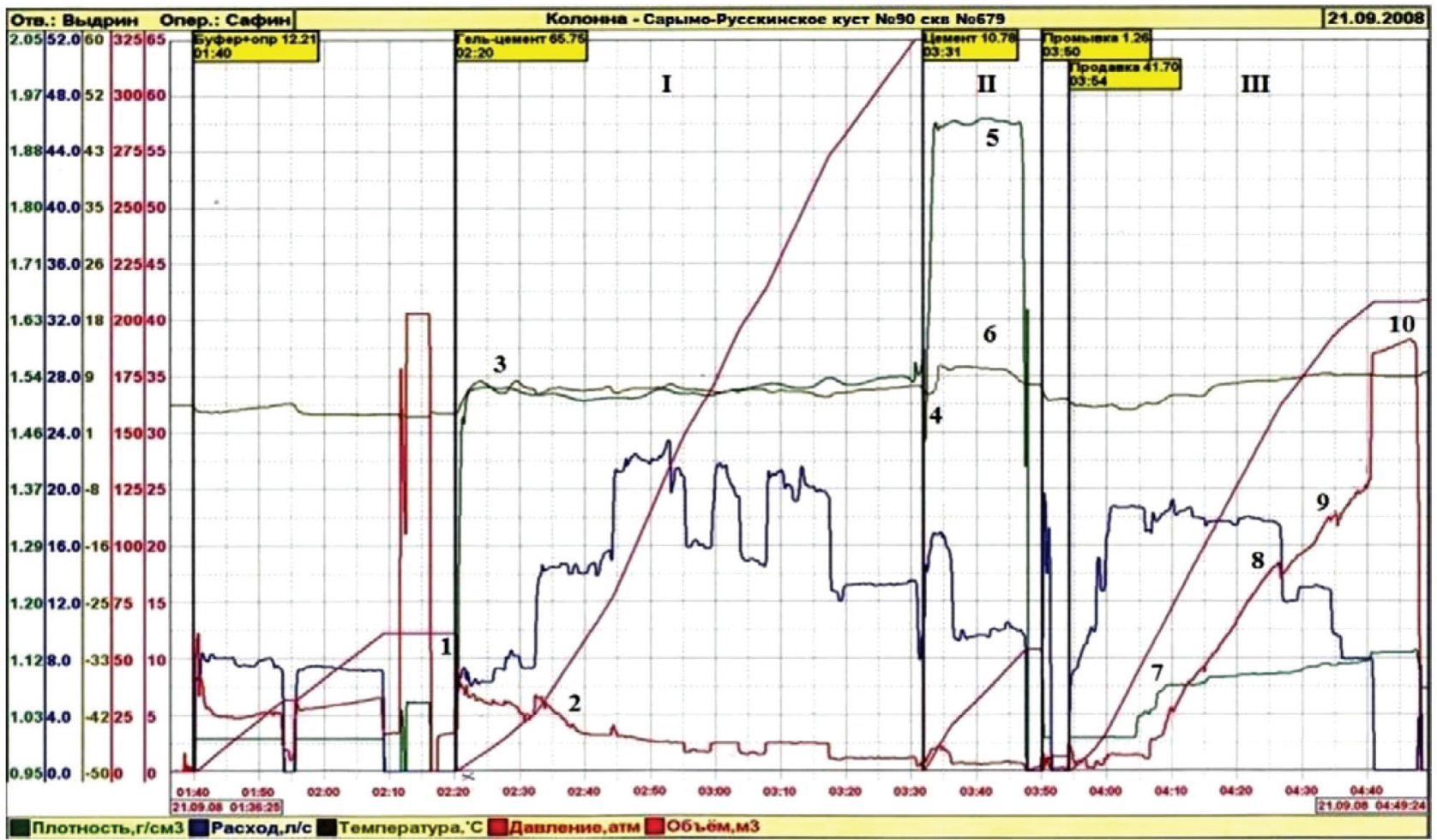

Рис. Цементограмма процесса цементирования эксплуатационной колонны в скважине Сарымо-Русскинского месторождения: I - этап закачивания гельце-

ментного раствора; II - этап закачивания цементного раствора; III - этап продавливания тампонажных растворов; 1 - начало процесса цементирования;

2 - нарушение сплошности потока жидкости в колонне обсадных труб;

3,4 - закачивание гельцементного раствора $\rho_{1}=1,50$ г $/ \mathrm{cm}^{3}, 5-$ закачивание цементного раствора $\rho_{2}=1,83$ г $/ \mathrm{cm}^{3} ; 6$ - температурный режим циркуляции раствора; 7 - момент восстановления сплошности потока технологических жидкостей; 8, 9 - моменты нарушения герметичности ствола; 10 - давление «стоп»

в колонне обсадных труб критической высоты столба жидкости тампонажных растворов, гидростатическое давление которого становится выше гидростатического давления бурового раствора в заколонном пространстве (см. рис. позиция 1).

В нашем случае это произошло через 27 мин после закачивания в обсадную колонну $14,3 \mathrm{~m}^{3}$ гельцементного раствора плотностью 1500 кг $/ \mathrm{m}^{3}$, когда высота столба раствора достигла 635 м (см. рис. позиция 1). С этого момента давление на устье снизилось с 2,2 МПа до практически атмосферного (см. рис. позиция 2) и оставалось неизменным до восстановления сплошности потока продавочной жидкости и цементно- 
го раствора в процессе его подъема на расчетную высоту (см. рис. позиции 7,8$)$. В течение всего этого периода времени - 2 ч. 23 мин. (см. рис. позиции $2,3,4$ и 7) - процесс цементирования происходил спонтанно и бесконтрольно с достижением максимальных значений скорости подъема раствора в кольцевом пространстве и гидродинамических давлений на стенки скважины. В этот период наиболее вероятны частичные поглощения цементных растворов в интервалы проницаемых пород, гидроразрывы, флюидопроявления.

Гидравлическими особенностями процесса цементирования колонны в это время является гравитационное течение раствора в кольцевом пространстве сплошным потоком и разорванным - в условиях разряженного пространства обсадных труб. Закачиваемый в колонну поток тампонажного раствора при поступлении в трубы разрывается и в таком не связанном состоянии устремляется вниз до глубины расположения текущего уровня жидкости при отсутствии давления на устьевом манометре. И продолжается это до восстановления сплошности потока технологических жидкостей, отмечаемого возникновением давления на устье скважины (см. рис. позиция 7). В этот скрытый период цементирования обсадных колонн интенсифицируются процессы гидромеханического взаимодействия тампонажных растворов и интервалов флюидонасыщенных пластов. И одним из значимых последствий этих процессов становится изменение исходной плотности цементного раствора (табл. 1).

В дальнейшем более существенные и необратимые изменения исходных свойств цементного раствора и камня происходят на стадии ОЗЦ во время относительного термодинамического равновесия в скважине.

Оценка качества цементирования обсадных колонн эксплуатационных скважин нефтяных месторождений Западной Сибири проводилась на результатах исследований - метод гамма-гамма цементометрии (данные СГДТ). Анализ данных показал, что изменение плотности цементных растворов-камня в заколонном пространстве происходит по всей высоте его подъема. Протяженность интервалов составляет от 3,0 до 1425 м, при этом значения средней плотности гельцементных растворов колеблются в пределах 1,244-1,52 г/ $\mathrm{cm}^{3}$, снижаясь на отдельных участках до $1,17-1,3$ г/ $\mathrm{cm}^{3}$. Плотность цементных растворов-камня несколько выше: $1,27-1,48$ г $/ \mathrm{cm}^{3}$, а иногда достигает $1,27-1,99$ г $/ \mathrm{cm}^{3}$. Зависимость свойств цементных растворов от их плотности представлена в табл. 2. 
Таблица 2

Зависимость свойств тампонажного раствора-камня от водоцементного отношения

\begin{tabular}{|c|c|c|c|c|c|c|c|}
\hline \multirow{2}{*}{$\begin{array}{l}\text { Марка } \\
\text { цемента }\end{array}$} & \multirow{2}{*}{ В/Ц } & \multirow{2}{*}{$\begin{array}{c}\text { Условная } \\
\text { водоотдача, } \\
\text { см }^{3} 30 \text { мин. }\end{array}$} & \multirow{2}{*}{ 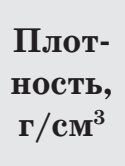 } & \multirow{2}{*}{$\begin{array}{l}\text { Водоотде- } \\
\text { ление, мл }\end{array}$} & \multirow{2}{*}{$\begin{array}{l}\text { Растекае- } \\
\text { мость, } \\
\text { мм }\end{array}$} & \multicolumn{2}{|c|}{$\begin{array}{c}\text { Прочность цементного } \\
\text { камня, МПа }\end{array}$} \\
\hline & & & & & & изгиб & сжатие \\
\hline ПцТ Ц-50 & 0,45 & 139,04 & 1,86 & 0 & 180 & 4,93 & 15,6 \\
\hline ПцТ Ц-50 & 0,5 & 164,32 & 1,83 & 0,2 & 220 & 5,72 & 11,3 \\
\hline ПцТ Ц-50 & 0,55 & 189,6 & 1,79 & 1,5 & 230 & 3,69 & 8,64 \\
\hline ПцТ Ц-50 & 0,6 & 208,56 & 1,76 & 3 & 250 & 2,87 & 8,56 \\
\hline ПЦТ Ц-50 & 0,65 & 208,56 & 1,74 & 5 & 270 & 2,45 & 5,68 \\
\hline ПЦТ Ц-50 & 0,7 & 214,88 & 1,71 & 5,8 & $>270$ & 2,08 & 4,96 \\
\hline
\end{tabular}

Необходимо отметить, что подобные результаты цементирования скважин, отмеченные в Западной Сибири, характерны для подавляющего большинства нефтяных и газовых месторождений в нашей стране и за рубежом. По результатам представленных данных наших исследований можно заключить, что для столь сложной природно-технической системы «скважина - техническая крепь» использование традиционных технологий цементирования, адекватных термодинамическим условиям их применения, в настоящее время не имеет перспектив. В этой связи для успешного решения этой сложнейшей технологической проблемы необходимо привлечение системных научно-технических подходов и решений. Как показывает промысловый опыт, в этом плане перспективно применение комплекса мультитехнологий гидромеханического упрочнения ствола (КМГУС) в процессе бурения и заканчивания нефтяных и газовых скважин в различных по сложности геолого-технических условиях $[1,14]$. КМГУС исключает возникновение различных осложнений в процессе строительства нефтяных и газовых скважин, таких как: поглощения интенсивностью до 50 м $^{3} /$ ч, газонефтеводопроявления, гидроразрывы и неустойчивость вскрытого массива горных пород, выбросы и фонтаны. В процессе эксплуатации скважин предупреждаются: заколонные флюидопроявления и межпластовые перетоки. Дебиты вышедших из бурения скважин в 2 и более раз выше, чем при традиционных технологиях строительства скважин, обводнен- 
ность добываемой продукции ниже более, чем в 2 раза, и как результат эксплуатации - нелинейно возрастают конечные показатели КИН.

В заключение отметим низкие эксплуатационные затраты на применение КМГУС (не превышают 1000-1500 тыс. руб.), высокое качество и эффективность буровых работ и экологическую безопасность.

\section{Библиографический список:}

1. Поляков B.H. Технология заканчивания нефтяных и газовых скважин / В.Н. Поляков, Р.К. Ишкаев, Р.Р. Лукманов. - Уфа: ТАУ, 1999. - 408 с.

2. Мирзаджанзаде А.Х. Гидравлика в бурении и цементировании скважин / А.Х. Мирзаджанзаде, А.К. Караев, С.А. Ширинзаде. - М.: Недра, 1977. - 230 с.

3. Мухалетшин В.В., Кадыров Р.Р. Влияние нанодобавок на механические и водоизолирующие свойства составов на основе цемента / Нанотехнологии в строительстве. - 2017. - Том 9, № 6. - C. 18-36. - DOI: dx.doi.org/10.15828/20758545-2017-9-6-18-36.

4. Andreev A.V. Deposit Productivity Forecast in Carbonate Reservoirs with Hard to Recover Reserves / A.V. Andreev, V.Sh. Mukhametshin, Yu.A. Kotenev / SOCAR Proceedings, 2016. № 3. P. 40-45. DOI: dx.doi.org/10.5510/OGP20160300287.

5. Prospects of Application of Multi-Functional Well Killing Fluids in Carbonate Reservoirs / Yu.V. Zeigman, V.Sh. Mukhametshin, A.R. Khafizov, S.B. Kharina // SOCAR Proceedings, 2016. № 3. P. 33-39. DOI: dx.doi.org/10.5510/ OGP20160300286.

6. The Usage of Principles of System Geological-Technological Forecasting in the Justification of the Recovery Methods / V.V. Mukhametshin, V.E. Andreev, G.S. Dubinsky, Sh.Kh. Sultanov, R.T. Akhmetov // SOCAR Proceedings, 2016. № 3. P. 46-51. DOI: dx.doi.org/10.5510/OGP20160300288.

7. Ахлетов P.T., Андреев А.В., Мухаметшин В.В. Методика прогноза остаточной нефтенасыщенности и коэффициента вытеснения по данным геофизических исследований для оценки эффективности применения нанотехнологий // Нанотехнологии в строительстве. - 2017. - Том 9, № 5. - C. 116-133. - DOI: dx.doi.org/10.15828/2075-8545-2017-9-5-116-133.

8. Зейглан Ю.В., Мухалетшин В.Ш., Сергеев В.В., Кинзябаев Ф.С. Экспериментальное исследование вязкостных свойств эмульсионных систем с содержанием наночастиц $\mathrm{SiO}_{2} / /$ Нанотехнологии в строительстве. - 2017. - Том 9, № 2. C. 16-38. - DOI: dx.doi.org/10.15828/2075-8545-2017-9-2-16-38. 
9. Мухалетшин В.Ш., Зейглан Ю.В., Андреев А.В. Экспресс-оценка потенциала добывных возможностей залежей для определения эффективности применения нанотехнологий и необходимости стимулирования ввода их в разработку // Нанотехнологии в строительстве. - 2017. - Том 9, № 3. - С. 20-34. - DOI: dx.doi.org/10.15828/2075-8545-2017-9-3-20-34.

10. Мухалетшин В.В. Устранение неопределенностей при решении задач воздействия на призабойную зону скважин // Известия Томского политехнического университета. Инжиниринг георесурсов. - 2017. - Т. 328, № 7. - С. 40-50.

11. Хайрединов Н.Ш. Повышение эффективности заводнения низкопродуктивных залежей нефти в карбонатных коллекторах / Н.Ш. Хайрединов, А.М. Попов, В.Ш. Мухаметшин // Нефтяное хозяйство. - 1992. - № 9. - С. 18-20.

12. Мухалетшин В.Ш. Зависимость нефтеизвлечения от плотности сетки скважин при разработке низкопродуктивных карбонатных залежей // Нефтяное хозяйство. - 1989. - № 12. - С. 26-29.

13. Mukhametshin V. Search and Argumentation of Decisions Aimed at Increasing the Efficiency of Bottom-Hole Zone Stimulation in Oil Accumulations with Challenged Reserves / V. Mukhametshin, V. Andreev // SPE Russian Petroleum Technology Conference. Moscow, Russia, 2017. P. 1-23. DOI: dx.doi. org/10.2118/187785-MS.

14. Поляков В.H. Требования, предъявляемые к герметичности и прочности ствола при заканчивании скважин месторождений Башкирии // Нефтяное хозяйство. - 1983. - № 5. - С. 27-28.

15. Повышение эффективности разобщения и изоляции продуктивных пластов при их разбуривании / В.Н. Поляков, Р.Р. Лукманов, А.У. Шарипов и др. // II Бурение: реф. науч.-техн. сб. - М.: ВНИИОЭНГ, 1979. - № 9. - С. 8-12.

16. Поляков B.H. О влиянии процессов деструкции и деградации на технологию бурения и заканчивания скважин // II открытая научно-практическая конференция «Актуальные проблемы строительства и ремонта нефтегазовых скважин на суше и континентальном шельфе РФ»: сб. док. - ООО «НПО Бентотехнологии», 2013. - С. 113-118.

17. Ашрафьян M.О. Технология разобщения пластов в осложненных условиях. М.: Недра, 1989. - 228 с.

18. Решение проблем заканчивания и эксплуатации скважин в аномальных термодинамических условиях / В.Н. Поляков, Ю.С. Кузнецов, И.А. Сагидуллин, Н.Ю. Шульгина, В.С. Дубровский, В.М. Хусаинов, Н.И. Хаминов, Р.Г. Ахметзянов, А.А. Вильданов, О.Е. Старов // Нефтяное хозяйство. - 2005. - № 5. C. $104-110$. 


\section{УВАЖАЕМЫЕ КОЛЛЕГИ!}

ПРИ ИСПОЛЬЗОВАНИИ МАТЕРИАЛА ДАННОЙ СТАТЬИ

ПРОСИМ ДЕЛАТЬ БИБЛИОГРАФИЧЕСКУЮ ССЫЛКУ НА НЕЁ:

Поляков В.Н., Зейгман Ю.В., Котенёв Ю.А., Мухаметшин В.В., Султанов Ш.Х., Чижов А.П. Системное решение технологических проблем заканчивания строительства скважин // Нанотехнологии в строительстве. - 2018. - Том 10, № 1. - C. 72-87. - DOI: dx.doi.org/10.15828/2075-8545-2018-10-1-72-87.

\section{DeAr Colleagues!}

THE REFERENCE TO THIS PAPER HAS THE FOLLOWING CITATION FORMAT:

PolyakovV.N.,Zeigman Yu.V., Kotenev Yu.A., Mukhametshin V.V., Sultanov Sh.Kh., Chizhov A.P. System solution for technological problems of well construction completion. Nanotehnologii v stroitel'stve = Nanotechnologies in Construction. 2018, Vol. 10, no. 1, pp. 72-87. DOI: dx.doi.org/10.15828/2075-8545-2018-10-1-7287. (In Russian). 